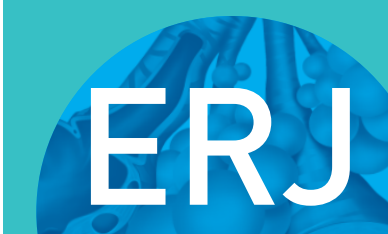

open research
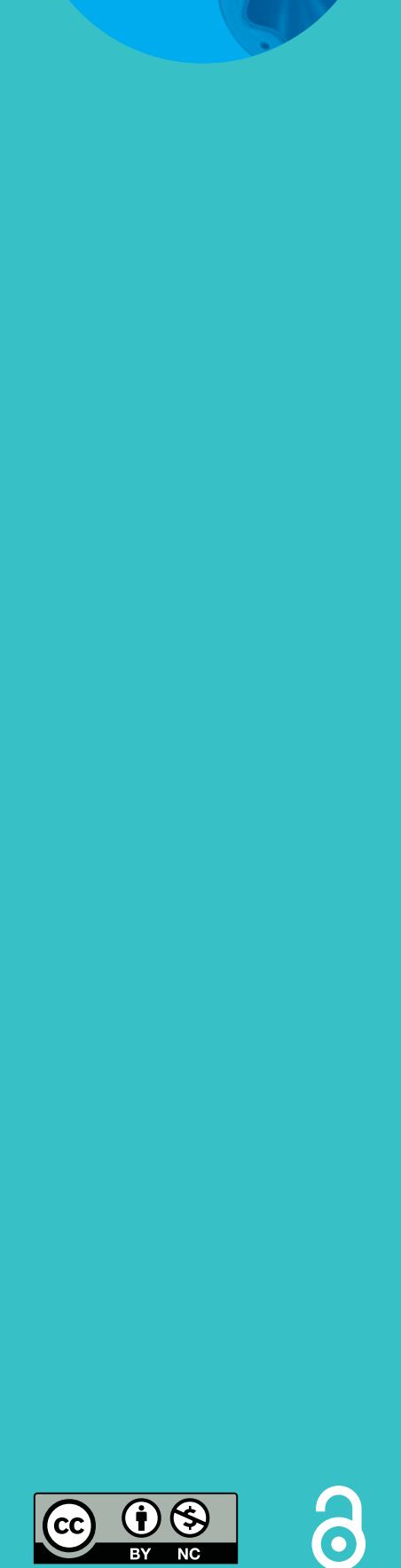

\section{Leaks during multiple-breath washout: characterisation and influence on} outcomes

\author{
Nina Lenherr ${ }^{1}$, Kathryn A. Ramsey $\mathbb{( D}^{2}$, Kerstin Jost ${ }^{1}$, Linn Hornwall ${ }^{1}$, \\ Florian Singer (10 ${ }^{2,3}$, Sophie Yammine ${ }^{2}$ and Philipp Latzin ${ }^{2}$
}

Affiliations: 'Dept of Pediatric Pneumology, University Children's Hospital Basel (UKBB), Basel, Switzerland. ${ }^{2}$ Pediatric Respiratory Medicine, Dept of Pediatrics, Inselspital, Bern University Hospital, University of Bern, Bern, Switzerland. ${ }^{3}$ Division of Respiratory Medicine, University Children's Hospital Zurich, Zurich, Switzerland.

Correspondence: Philipp Latzin, Pediatric Respiratory Medicine, Dept of Pediatrics, Inselspital, Bern University Hospital, University of Bern, Freiburgstrasse, Bern 3010, Switzerland.

E-mail: philipp.latzindinsel.ch

ABSTRACT Nitrogen multiple-breath washout $\left(\mathrm{N}_{2} \mathrm{MBW}\right)$ is increasingly used in patients with cystic fibrosis. The current European Respiratory Society/American Thoracic Society consensus statement for MBW recommends the rejection of measurements with leaks. However, it is unclear whether this is necessary for all types of leaks. Here, our aim was to 1) model and 2) apply air leaks, and 3) to assess their influence on the primary MBW outcomes of lung clearance index and functional residual capacity.

We investigated the influence of air leaks at various locations (pre-, intra- and post-capillary), sizes, durations and stages of the washout. Modelled leaks were applied to existing $\mathrm{N}_{2} \mathrm{MBW}$ data from 10 children by modifying breath tables. In addition, leaks were applied to the equipment during $\mathrm{N}_{2} \mathrm{MBW}$ measurements performed by one healthy adolescent.

All modelled and applied leaks resulted in statistically significant but heterogeneous effects on lung clearance index and functional residual capacity. In all types of continuous inspiratory leaks exceeding a certain size, the end of the washout was not reached. For practical application, we illustrated six different "red flags", i.e. signs that enable easy identification of leaks during measurements.

Air leaks during measurement significantly influence $\mathrm{N}_{2} \mathrm{MBW}$ outcomes. The influence of leaks on MBW outcomes is dependent on the location, relation to breath cycle, duration, stage of washout and size of the leak. We identified a range of signs to help distinguish leaks from physiological noise.

@ERSpublications

The influence of leaks on nitrogen MBW outcomes is complex, dynamic and dependent on the size, duration, location and position of leaks during the washout and breathing cycle http://ow.ly/PbHV30hB91H

Cite this article as: Lenherr N, Ramsey KA, Jost K, et al. Leaks during multiple-breath washout: characterisation and influence on outcomes. ERJ Open Res 2018; 4: 00012-2017 [https://doi.org/ $10.1183 / 23120541.00012-2017]$.

This article has supplementary material available from openres.ersjournals.com

Received: Jan 292017 | Accepted after revision: Dec 132017

Support statement: This research was funded by the Swiss Society of Cystic Fibrosis $(\mathrm{CFCH})$, Foundation Botnar, and University of Basel and UKBB. The funders had no role in study design, data collection and analysis, decision to publish or preparation of the manuscript. Funding information for this article has been deposited with the Crossref Funder Registry.

Conflict of interest: None declared.

Copyright $\odot$ ERS 2018. This article is open access and distributed under the terms of the Creative Commons Attribution Non-Commercial Licence 4.0. 


\section{Introduction}

The multiple-breath washout (MBW) technique was established to measure ventilation inhomogeneity as a marker of small airway function [1,2]. The main outcome of MBW is the lung clearance index (LCI), a global marker of ventilation inhomogeneity, which has been shown to be abnormal in patients with cystic fibrosis (CF) lung disease [3-9]. In individuals with CF, LCI has been used as an end-point in intervention trials $[10,11]$ and in some centres is used for routine clinical surveillance [12]. The quality of MBW data is dependent on airtight gas sampling during measurement. However, in practice, leaks occur frequently during MBW measurements [7].

Leaks are gaps in the breathing circuit, which can occur at the subject-equipment interface (e.g. insufficient closure of the mouth or coughing; pre-capillary), within the equipment (e.g. damaged Nafion tube; intra-capillary) or between the equipment and gas supply (post-capillary). Depending on the location of the leak and stage in the breathing cycle, leaks can either add or remove tracer gas from the system and artificially change MBW outcomes. Leaks during MBW measurements are not always easy to identify. Suboptimal BTPS (body temperature, ambient pressure, saturated) correction or signal alignment may distort the tracer gas signal and mimic leaks [13]. In patients with advanced lung disease, leaks may be difficult to distinguish from increased ventilation inhomogeneity as both may increase washout duration considerably [14].

The specific impact of leaks on LCI is unclear $[15,16]$. However, the recent European Respiratory Society (ERS)/American Thoracic Society (ATS) MBW consensus statement strongly suggests that all measurements with a suspected leak should be excluded [15]. Considering the fact that three technically acceptable MBW trials should be obtained [15], this may be time consuming and exhaustive for the subject. It is important to know whether all measurements with suspected leaks should be discarded or whether certain leaks may be acceptable because their impact on LCI is minimal.

The aim of this study was to characterise different types of leaks during nitrogen MBW $\left(\mathrm{N}_{2} \mathrm{MBW}\right)$ and to investigate their influence on LCI and functional residual capacity (FRC). Leaks were 1) modelled by applying them to existing $\mathrm{N}_{2} \mathrm{MBW}$ data from 10 children by modifying breath tables and 2) applied to the equipment during real-time $\mathrm{N}_{2} \mathrm{MBW}$ measurements for a healthy individual. The primary outcome of the study was the change in LCI and FRC compared with baseline following the application of leaks. For practical application we aimed to identify key signs indicative of leaks during $\mathrm{N}_{2} \mathrm{MBW}$ measurement.

\section{Methods}

\section{Study design and subjects}

We performed an experimental study by modelling air leaks into existing MBW measurements at varying locations, duration and breath cycle during the washout. Modelled leaks were applied to existing quality controlled $\mathrm{N}_{2} \mathrm{MBW}$ data originally collected in five healthy children and five children with CF aged 8-17 years. To verify the influence of modelled air leaks, a range of leaks were applied to the equipment during $\mathrm{N}_{2} \mathrm{MBW}$ measurements in a healthy female adolescent. This study was approved by the Ethics Committee Basel and Bern (Switzerland). The children's assent was obtained and parents and adolescents provided written informed consent for this study.

\section{Nitrogen multiple-breath washout}

$\mathrm{N}_{2}$ MBW measurements were performed using $100 \%$ oxygen $\left(\mathrm{O}_{2}\right)$ and commercially available equipment (Exhalyzer D and Spiroware version 3.1.6; Eco Medics, Duernten, Switzerland) [17] according to current ERS/ATS consensus guidelines [15]. $\mathrm{N}_{2}$ concentration was calculated indirectly from the $\mathrm{O}_{2}$ and carbon dioxide $\left(\mathrm{CO}_{2}\right)$ fractions. The primary outcomes from the MBW technique were LCI and FRC. Details on how LCI and FRC are calculated, as well as measurement and leak algorithms, are provided in the supplementary material. LCI is calculated as the cumulative expired volume of tracer gas divided by FRC. Therefore, it is possible that leaks in the system resulting in changes in FRC and cumulative expired volume of the same magnitude and direction may not lead to changes in LCI.

\section{Modelling different leak types}

In general, leaks may affect measurement of gas concentration, gas volume and tidal volume. We categorised the following five distinct leak characteristics.

\section{Location}

We modelled four different leak locations (figure 1): pre-capillary, intra-capillary (including main- and side-stream locations) and post-capillary leaks. "Capillary" corresponds to the two gas sampling points $\left(\mathrm{CO}_{2}\right.$ and $\left.\mathrm{O}_{2}\right)$ and is distinct from the flow meter. "Pre-capillary" is between the patient and sampling point (e.g. patient interface; when the nose clip or mouthpiece are not positioned correctly). 


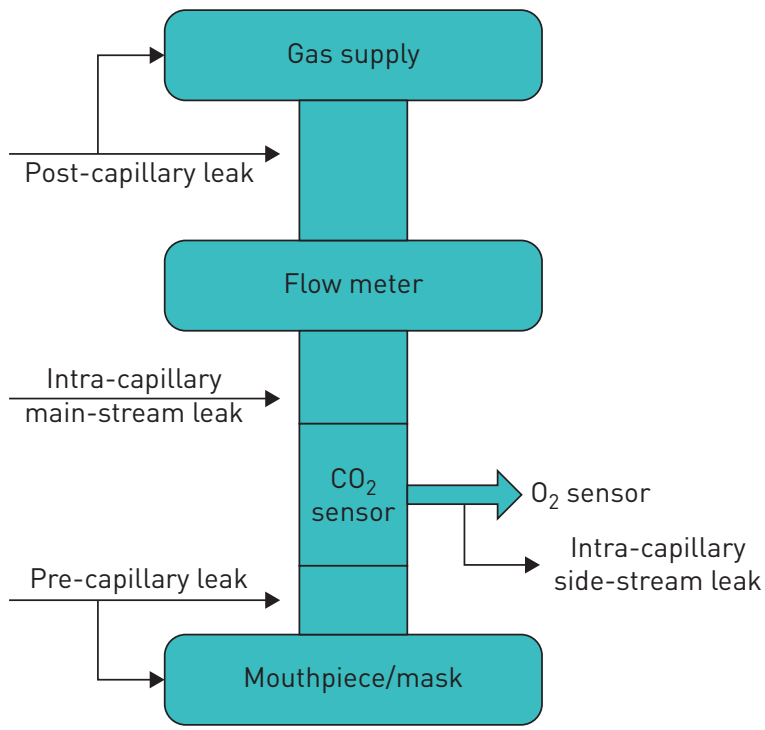

FIGURE 1 Different locations of leaks in relation to the sensor and flow meter. Pre-capillary leak: between the patient and sensor. Intra-capillary main-stream leak: between the sensor and flow meter. Intra-capillary side-stream leak: between the carbon dioxide $\left(\mathrm{CO}_{2}\right)$ sensor and oxygen $\left(\mathrm{O}_{2}\right)$ sensor. Post-capillary leak: between the flow meter and gas supply.

"Intra-capillary" is subdivided into 1) "main-stream" between the $\mathrm{CO}_{2}$ sensor and flow meter (e.g. loose plastic inserts) and 2) "side-stream" between the $\mathrm{CO}_{2}$ and $\mathrm{O}_{2}$ sensor (e.g. damaged Nafion tube), and occurs independent of breath cycle due to constant flow into the side-stream. "Post-capillary" is between the gas sampling point and gas supply from bias flow.

Relation to the breath cycle

We applied leaks during either inspiration, expiration or the whole tidal breath (inspiration and expiration).

\section{Duration}

We modelled two different leak durations: isolated leaks (occurring across two consecutive breaths) and continuous leaks (occurring from the moment applied to the end of the washout).

Stage of washout

We applied leaks during the following washout phases: the first washout breath, and after one-quarter, one-half and three-quarters of the washout time.

\section{Size of leak}

The size of the leak was defined and modelled relative to the tidal volume $(V T)$. Different leak sizes of $10 \%, 20 \%$ and $50 \% V \mathrm{~T}$ were introduced into the leak model. Comparable algorithms have been used to assess leaks around a tracheal tube in mechanically ventilated lung models $[18,19]$.

\section{Application of different leak types}

Modelled leaks

Modelled leaks were applied according to the above criteria to existing MBW data by modifying breath tables (supplementary table S1). We modified the $V$ T and/or end-tidal or inspiratory $\mathrm{N}_{2}$ concentrations breath by breath according to the specific characteristics of each leak type.

\section{Applied leaks}

We inserted artificial leaks into the setup during real-time $\mathrm{N}_{2} \mathrm{MBW}$ measurements. One healthy adolescent performed a total of $22 \mathrm{~N}_{2} \mathrm{MBW}$ measurements, including 1) four standard high-quality tests without leaks, 2) 15 measurements with pre-capillary leaks (seven continuous and eight isolated inspiratory and expiratory leaks during four stages of the washout; applied from the start, one-quarter, one-half and three-quarters of the washout), and 3) two measurements with intra-capillary leaks (one main-stream and one side-stream continuous inspiratory and expiratory leak), and one measurement with post-capillary continuous inspiratory and expiratory leak. 


\section{Statistics}

The primary MBW outcomes, LCI and FRC, from the original measurement without leak were set as the baseline values. Generated LCI and FRC values after the insertion of leaks were compared with baseline values by paired t-tests. The difference between the baseline and generated LCI and FRC values provided an estimate of the error resulting from the applied leaks. p-values $<0.05$ were considered statistically significant. All analyses were performed using Stata/IC version 11 (StataCorp, College Station, TX, USA).

\section{Results}

In total, 29 different leaks were applied to $\mathrm{N}_{2} \mathrm{MBW}$ measurements from five children with $\mathrm{CF}$ and five healthy controls, leading to a total of 290 modified MBW measurements. In addition, 22 leaks were applied to the setup during real-time measurements in a healthy adolescent.

\section{Influence of modelled leaks on washout outcomes}

All types of leaks had systematic, i.e. nonrandom, effects on the washout outcomes FRC and LCI. The size and direction of the effect on FRC and LCI differed for each leak type (table 1). Results of leaks modelled retrospectively to existing measurements were confirmed by real-time application of leaks to the setup. We summarise the effects of different leak characteristics in the following subsections.

\section{Location and breathing cycle}

For continuous and isolated inspiratory and combined inspiratory and expiratory leaks, FRC and LCI increased independent of leak location (pre-, intra- and post-capillary). In contrast, expiratory leaks resulted in changes to FRC and LCI that were dependent on leak location and duration (tables 1 and 2). Generally, continuous pre-capillary expiratory leaks resulted in decreased FRC and LCI for leaks applied after one-quarter of the washout (table 2). Continuous intra-capillary expiratory leaks led to significant decreases in FRC but did not change LCI, while continuous post-capillary expiratory leaks did not affect either LCI or FRC.

For isolated expiratory leaks, in most cases FRC was underestimated, while LCI did not change (table 2). In contrast, for isolated inspiratory leaks exceeding a certain size and duration, the end of washout criteria were not reached, and therefore FRC and LCI could not be calculated. Applying a similar pre-capillary leak during inspiration during a real-time measurement resulted in an end-tidal $\mathrm{N}_{2}$ concentration stabilising at $\sim 10 \%$ and thus precluded washout completion. Due to the fact that the end-of-test criteria could not be reached, we were unable to generate FRC and LCI outcomes for many measurements with inspiratory and combined inspiratory and expiratory leaks.

\section{Duration}

The influence of leaks on washout outcomes largely depends on their duration. In general, the influence of continuous leaks on LCI and FRC was larger than the influence of isolated leaks (figure 2). Continuous pre-capillary expiratory leaks of $20 \%$ resulted in decreases in LCI and FRC, while the same type of isolated leak over two tidal breaths after one-quarter of the full washout time resulted in small changes in LCI and

TABLE 1 Influence of leak location and breathing cycle on functional residual capacity (FRC) and lung clearance index (LCI): overview of the influence of continuous leaks on FRC and LCI applied at different locations and phases of the breath cycle

\begin{tabular}{|c|c|c|c|c|}
\hline & \multirow[t]{2}{*}{ Pre-capillary } & \multicolumn{2}{|c|}{ Intra-capillary } & \multirow[t]{2}{*}{ Post-capillary } \\
\hline & & Side-stream & Main-stream & \\
\hline \multirow[t]{2}{*}{ Inspiratory } & $\mathrm{FRC} \uparrow^{\#}$ & $N A^{\pi}$ & $\mathrm{FRC} \uparrow^{\#}$ & $\mathrm{FRC} \uparrow^{\#}$ \\
\hline & $\mathrm{LCl} \uparrow^{\#}$ & NA" & $\mathrm{LCl} \uparrow^{\#}$ & $\mathrm{LCl} \uparrow^{\#}$ \\
\hline \multirow[t]{2}{*}{ Expiratory } & FRC $\downarrow$ & $N A^{\pi}$ & FRC $\downarrow$ & $\mathrm{FRC}-$ \\
\hline & $\mathrm{LCl}-/ \downarrow^{+}$ & $N A^{\pi}$ & $\mathrm{LCl}-$ & $\mathrm{LCl}-$ \\
\hline \multirow[t]{2}{*}{ Inspiratory and expiratory } & $\mathrm{FRC} \uparrow^{\#}$ & $\mathrm{FRC} \uparrow^{\#}$ & FRC $\uparrow^{\#}$ & FRC $\uparrow^{\#}$ \\
\hline & $\mathrm{LCl} \uparrow^{\#}$ & $\operatorname{LCl} \uparrow^{\#}$ & $\mathrm{LCl} \uparrow^{\#}$ & $\operatorname{LCl} \uparrow^{\#}$ \\
\hline \multicolumn{5}{|c|}{ 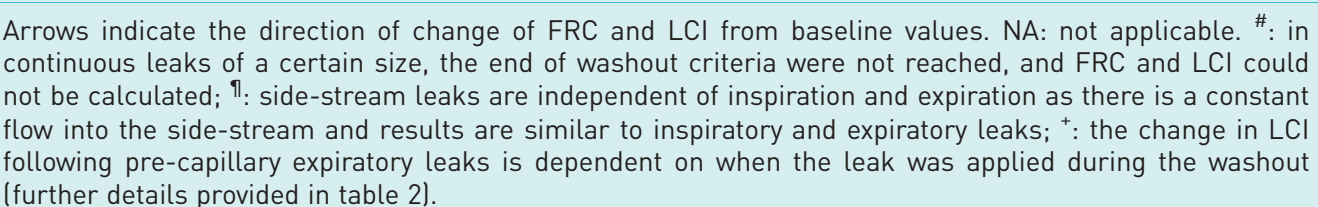 } \\
\hline
\end{tabular}



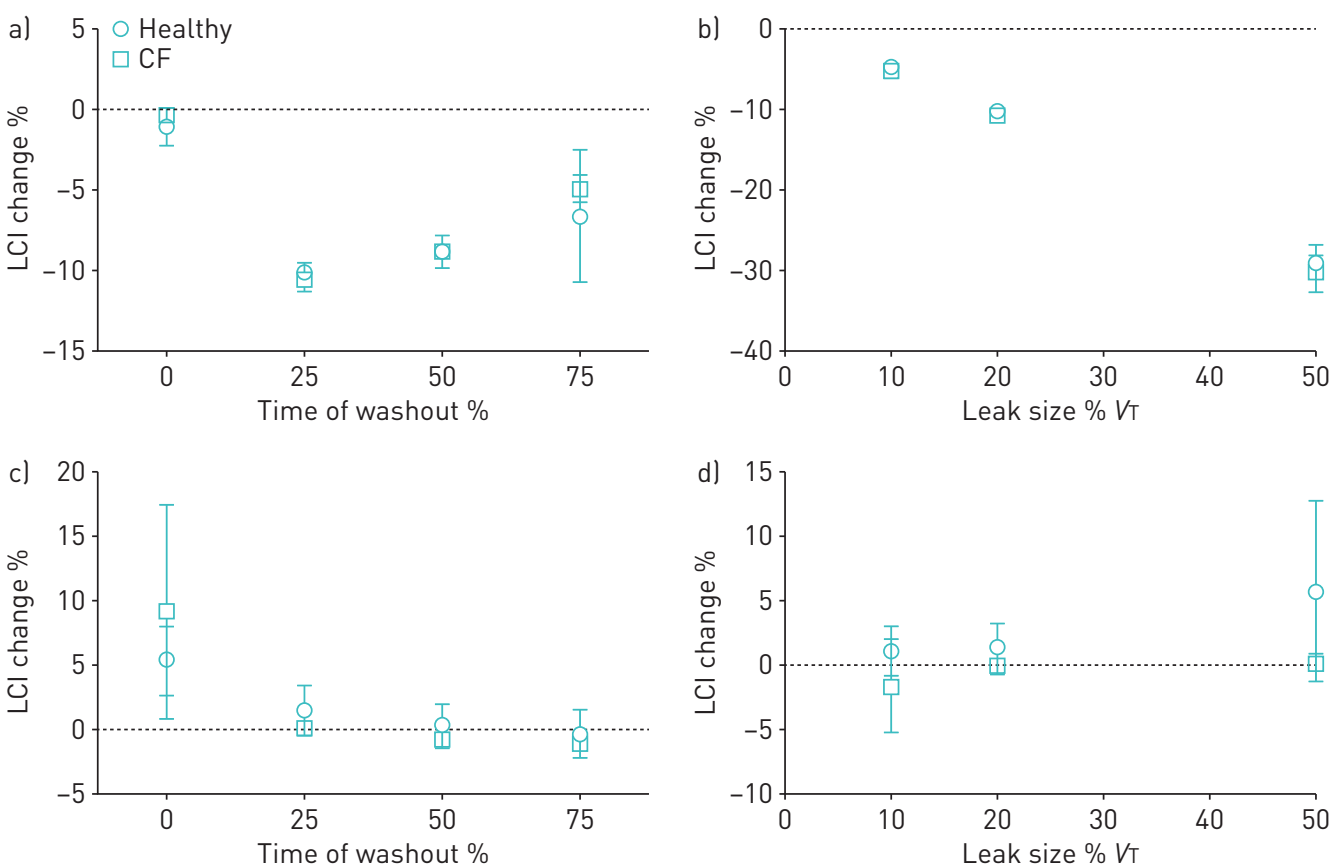

FIGURE 2 Change in lung clearance index (LCI) (mean \pm SD \% change lung turnovers compared with baseline) based on modelled $a, b)$ continuous and $c, d$ ) isolated pre-capillary expiratory leaks in healthy children and children with cystic fibrosis (CF). VT: tidal volume. al Continuous $20 \% V_{T}$ leak. b) Continuous leaks after one-quarter washout. c) Isolated 20\% VT leak. d) Isolated leaks after one-quarter washout. Isolated leaks were defined as occurring over two breaths.

\section{Flow-volume loop}

The flow-volume loop is altered in pre-capillary or intra-capillary main-stream leaks. In inspiratory leaks, expiratory volume is larger than inspiratory volume, and vice versa, leading to a visible step-change in the flow-volume curve at the transition from inspiration to expiration. In leaks of comparable size occurring during inspiration and expiration, $V \mathrm{~T}$ is smaller than usual and can be identified if the estimated normal $V$ T range is given (supplementary figure S2).

Step-change in volume trace

Sudden step-changes in volume or changes in direction of the volume drift are signs of pre-, intra- or post-capillary leaks. This is especially true if no change in breathing pattern is visible (supplementary figure S3).

\section{Premature rise in $\mathrm{N}_{2}$ signal}

Spikes (distorted $\mathrm{N}_{2}$ expirograms) may occur in all types of leaks and indicate bias from ambient $\mathrm{N}_{2}$. In the Exhalyzer D setup, $\mathrm{N}_{2}$ spikes must be accompanied by a mirror-inverted drop of the $\mathrm{O}_{2}$ signal to differentiate from $\mathrm{N}_{2}$ spikes due to $\mathrm{O}_{2}-\mathrm{CO}_{2}$ signal misalignment (supplementary figure $\mathrm{S} 3$ ).

\section{Sudden spike in $\mathrm{N}_{2}$ concentration during inspiration}

A step-up of end-tidal $\mathrm{N}_{2}$ concentration is a sign of an inspiratory leak. This $\mathrm{N}_{2}$ step-up must be accompanied by a mirror-inverted step-down or levelling of the $\mathrm{O}_{2}$ signal (supplementary figure S4).

\section{Elevated end-tidal N2 concentration}

A step-up of inspiratory $\mathrm{N}_{2}$ concentration $(>0.03 \%)$ occurs in inspiratory intra-capillary and post-capillary leaks. This rise in the inspiratory $\mathrm{N}_{2}$ fraction must be accompanied by a mirror-inverted decrease of the inspiratory $\mathrm{O}_{2}$ fraction (supplementary figure S5).

\section{Stabilisation of $\mathrm{N}_{2}$ concentration}

Stabilisation of $\mathrm{N}_{2}$ concentration occurs in all leaks appearing during inspiration. Depending on the size of the leak, the required end concentration of $\mathrm{N}_{2}$ is not reached and washout cannot be completed (supplementary figure S6). 

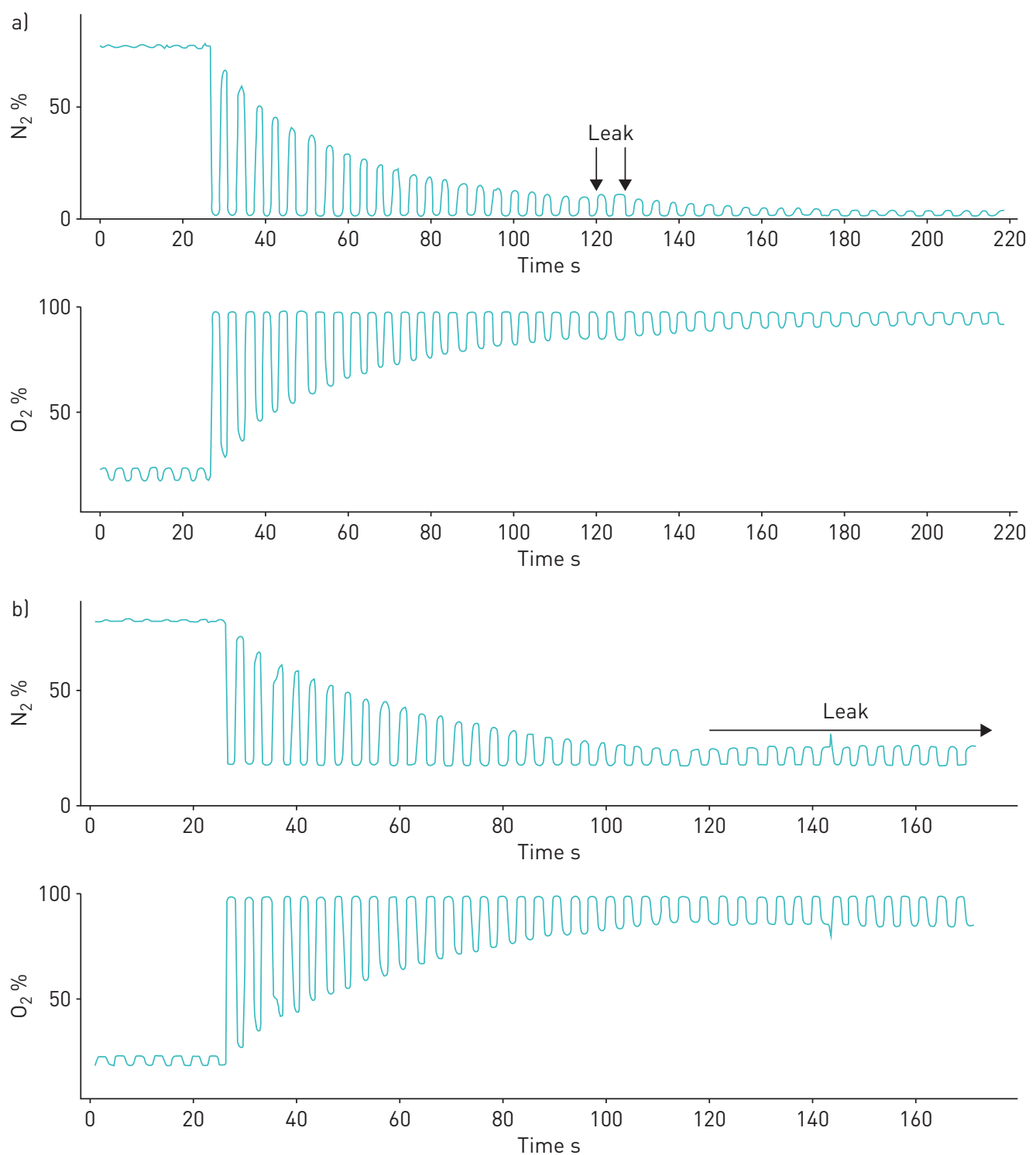

FIGURE 3 The impact of applied leaks on nitrogen $\left(\mathrm{N}_{2}\right)$ and oxygen $\left(\mathrm{O}_{2}\right)$ traces in a healthy adolescent individual: pre-capillary inspiratory and expiratory leaks of the same size and at the same stage of washout were applied with differences in duration. a) Temporary leak of two tidal breaths resulting in elevated functional residual capacity (FRC) and lung clearance index (LCI). b) Continuous leak resulting in stabilised elevation of expiratory end-tidal $\mathrm{N}_{2}$ concentration and end of washout criteria not being reached (FRC and LCI cannot be calculated].

\section{Discussion}

This study is the first to systematically identify and assess the effect of air leaks on MBW outcomes. The influence of leaks on MBW outcomes depends upon several characteristics: location in the setup, relation to breathing cycle, duration, stage during washout and size of leak. The impact of leaks on FRC and LCI is complex, dynamic and influenced by a number of physiological factors.

\section{Interpretation of results}

The size, duration, location and position of leaks during the washout and breathing cycle influence MBW outcomes. Data on the prevalence of different kinds of leaks are missing, but based on our experience pre-capillary leaks (e.g. leaks in the subject-equipment interface) are the most common leaks during measurement [7]. These leaks generally lead to an overestimation in both FRC and LCI. However, pre-capillary leaks that occur only during expiration (e.g. insufficient closure of mouth or coughing) may lead to underestimation of both FRC and LCI. This demonstrates how the influence of leak characteristics on MBW results is complex. This complexity precludes simple criteria regarding test acceptance or 
rejection due to specific leak types. In contrast, post-capillary leaks (e.g. due to leaking gas supply) occur very rarely in $\mathrm{N}_{2} \mathrm{MBW}$ measurements. These leaks only change washout outcomes if they occur during inspiration, resulting in overestimation of LCI and FRC values. Intra-capillary leaks, such as small side-stream leaks (e.g. broken side-stream sampling tube), can be difficult to recognise. The only signs of these leaks can be slightly elevated inspiratory $\mathrm{N}_{2}$ concentration, elongated washout duration and increased LCI. If unnoticed, this leak type can persist for longer periods and ruin large sets of data, as the elevated FRC and LCI values cannot be corrected retrospectively.

\section{Methodical considerations}

Given the compound influences that leaks may have on MBW outcomes, we chose a semiquantitative approach to assess their influence. Those simplifications enabled us to disentangle different characteristics of leaks and their influence on washout outcomes. Despite a small sample size, we were able to identify statistically significant changes in FRC and LCI with the application of modelled leaks, which were confirmed in the real-time application of leaks during MBW measurements.

In real-life MBW measurements, the effect of leaks on $\mathrm{N}_{2}$ concentration and their influence on the calculation of FRC and LCI are highly complex. It is therefore very difficult to model leaks using breath tables from measurements that are leak free. It is particularly difficult to model complex leaks that occur over different regions of the breathing cycle and the influence of additional or reduced $\mathrm{N}_{2}$ on gas mixing in the lung over subsequent breaths. While we believe that our modelled leak data provides important information to help users understand how different leak types may influence outcomes, we cannot confidently state that the modelled leaks represent exactly what is seen in practice.

The current ERS/ATS consensus document provides criteria to identify leaks based on expert opinion [15]. The current lung model and methodological in vivo studies in MBW [20-22] did not systematically assess leaks. Previous studies have focused on the impact of tracheal tube air leaks on measurement of $V \mathrm{~T}$ [18, 23, 24] or $\mathrm{CO}_{2}$ in mechanically ventilated patients [19]. Further studies have used plastic lung models and demonstrated, similar to our data, that continuous leaks exceeding $20-40 \% V \mathrm{~T}$ distort the $\mathrm{CO}_{2}$ signal and lead to overestimation of respiratory system resistance.

\section{Limitations}

We acknowledge that some, but not all, of our results are specific for the device used. However, most MBW systems similarly incorporate main- and side-stream sensors with pre- and post-capillary compartments for $\mathrm{N}_{2} \mathrm{MBW}$ or sulfur hexafluoride $\mathrm{MBW}$ measurements [7, 20,25], and are thus prone to similar leaks. Another limitation of our study was the difficulty of modelling leaks during inspiration. Our air leak model presumed complete gas mixing in the lung after each inspiration of additional $\mathrm{N}_{2}$ following inspiratory leaks, which is a simplification. In addition, the criteria for leak size, duration and stage of washout were arbitrary, but considered realistic based on our experience. Additional studies may be useful to further examine different leak types, such as smaller leaks (e.g. 5\% VT) or leaks occurring in the final breaths of the washout. The adolescent performed repeated MBW measurements over a period of 3 days; however, we only assessed baseline, leak-free MBW measurements at the start and therefore could not calculate the inter-test variability of LCI or FRC in this individual.

\section{Relevance}

In practice, many washout tests are excluded because of suspected leaks, although differentiation between leaks and increased ventilation inhomogeneity is not always easy. In this regard, the systematic approach in our study may help users to identify leaks and understand their influence on MBW outcomes. Furthermore, it is possible that our data could be used to enable some measurements with identified leaks to be interpreted in clinical practice, e.g. a measurement with a normal LCI and temporary expiratory leak at the end of the washout due to coughing may be used to confirm the absence of increased ventilation inhomogeneity, as the LCI is expected to be overestimated with this type of leak. We found that all leak types influenced FRC and LCI outcomes, and therefore our data support the current ERS/ATS consensus guidelines that all MBW measurements with identifiable leaks should be rejected [15]. A recent multicentre study found that the intra-test variability within a single test occasion is $3.9 \%$ for healthy children and $4.9 \%$ for children with CF. In addition, LCI was stable in healthy children, but in children with CF LCI increased over time at a rate of 0.40 LCI units per year [26]. We believe that including trials with even small leaks could significantly increase the intra-test and inter-test variability of LCI. As a result, LCI would have a reduced ability to detect progression of disease over time and monitor response to therapies. Furthermore, our data aim to assist users in identifying the presence and location of leaks during MBW testing in order to improve overall data quality and feasibility. 


\section{Conclusions}

The influence of leaks on $\mathrm{N}_{2} \mathrm{MBW}$ outcomes is complex, dynamic and dependent on the size, duration, location and position of leaks during the washout and breathing cycle. We identified six signs that may help to identify leaks from other measurement errors or increased ventilation inhomogeneity. These data provide a platform for further development of MBW quality control criteria and automated leak detection.

\section{Acknowledgements}

The authors would like to thank all participants of the study.

\section{References}

1 Fuchs SI, Ellemunter H, Eder J, et al. Feasibility and variability of measuring the Lung Clearance Index in a multi-center setting. Pediatr Pulmonol 2012; 47: 649-657.

2 Jensen R, Stanojevic S, Gibney K, et al. Multiple breath nitrogen washout: a feasible alternative to mass spectrometry. PLoS One 2013; 8: e56868.

3 Owens CM, Aurora P, Stanojevic S, et al. Lung clearance index and HRCT are complementary markers of lung abnormalities in young children with CF. Thorax 2011; 66: 481-488.

4 Horsley AR, Gustafsson PM, Macleod KA, et al. Lung clearance index is a sensitive, repeatable and practical measure of airways disease in adults with cystic fibrosis. Thorax 2008; 63: 135-140.

5 Yammine S, Singer F, Gustafsson P, et al. Impact of different breathing protocols on multiple-breath washout outcomes in children. J Cyst Fibros 2014; 13: 190-197.

6 Kieninger E, Singer F, Fuchs O, et al. Long-term course of lung clearance index between infancy and school-age in cystic fibrosis subjects. J Cyst Fibros 2011; 10: 487-490.

7 Singer F, Kieninger E, Abbas C, et al. Practicability of nitrogen multiple-breath washout measurements in a pediatric cystic fibrosis outpatient setting. Pediatr Pulmonol 2013; 48: 739-746.

8 Pfleger A, Steinbacher M, Schwantzer G, et al. Short-term effects of physiotherapy on ventilation inhomogeneity in cystic fibrosis patients with a wide range of lung disease severity. J Cyst Fibros 2015; 14: 627-631.

9 Stanojevic S, Jensen R, Sundaralingam D, et al. Alternative outcomes for the multiple breath washout in children with CF. J Cyst Fibros 2015; 14: 490-496.

10 Subbarao P, Stanojevic S, Brown M, et al. Lung clearance index as an outcome measure for clinical trials in young children with cystic fibrosis. A pilot study using inhaled hypertonic saline. Am J Respir Crit Care Med 2013; 188: 456-460.

11 Davies J, Sheridan H, Bell N, et al. Assessment of clinical response to ivacaftor with lung clearance index in cystic fibrosis patients with a G551D-CFTR mutation and preserved spirometry: a randomised controlled trial. Lancet Respir Med 2013; 1: 630-638.

12 Subbarao P, Milla C, Aurora P, et al. Multiple-breath washout as a lung function test in cystic fibrosis. A Cystic Fibrosis Foundation Workshop Report. Ann Am Thorac Soc 2015; 12: 932-939.

13 Summermatter S, Singer F, Latzin P, et al. Impact of software settings on multiple-breath washout outcomes. PLoS One 2015; 10: e0132250.

14 Yammine S, Singer F, Abbas C, et al. Multiple-breath washout measurements can be significantly shortened in children. Thorax 2013; 68: 586-587.

15 Robinson PD, Latzin P, Verbanck S, et al. Consensus statement for inert gas washout measurement using multiple- and single-breath tests. Eur Respir J 2013; 41: 507-522.

16 Wanger J, Clausen JL, Coates A, et al. Standardisation of the measurement of lung volumes. Eur Respir J 2005; 26 : 511-522.

17 Singer F, Houltz B, Latzin P, et al. A realistic validation study of a new nitrogen multiple-breath washout system. PLoS One 2012; 7: e36083.

18 Kondo T, Matsumoto I, Lanteri CJ, et al. Respiratory mechanics during mechanical ventilation: a model study on the effects of leak around a tracheal tube. Pediatr Pulmonol 1997; 24: 423-428.

19 Schmalisch G, Al-Gaaf S, Proquitte H, et al. Effect of endotracheal tube leak on capnographic measurements in a ventilated neonatal lung model. Physiol Meas 2012; 33: 1631-1641.

20 Gonem S, Singer F, Corkill S, et al. Validation of a photoacoustic gas analyser for the measurement of functional residual capacity using multiple-breath inert gas washout. Respiration 2014; 87: 462-468.

21 Schmidt A, Yammine S, Proietti E, et al. Validation of multiple-breath washout equipment for infants and young children. Pediatr Pulmonol 2015; 50: 607-614.

22 Benseler A, Stanojevic S, Jensen R, et al. Effect of equipment dead space on multiple breath washout measures. Respirology 2015; 20: 459-466.

23 Miyoshi E, Fujino Y, Uchiyama A, et al. Effects of gas leak on triggering function, humidification, and inspiratory oxygen fraction during noninvasive positive airway pressure ventilation. Chest 2005; 128: 3691-3698.

24 Singh R, Courtney SE, Weisner MD, et al. Respiratory mechanics during high-frequency oscillatory ventilation: a physical model and preterm infant study. J Appl Physiol 2012; 112: 1105-1113.

25 Gustafsson PM, Aurora P, Lindblad A. Evaluation of ventilation maldistribution as an early indicator of lung disease in children with cystic fibrosis. Eur Respir J 2003; 22: 972-979.

26 Stanojevic S, Davis SD, Retsch-Bogart G, et al. Progression of lung disease in preschool patients with cystic fibrosis. Am J Respir Crit Care Med 2017; 195: 1216-1225. 